\section{Democratização da cultura, práticas curriculares e o ensino da Educação Física nas escolas}

Rogério Rodrigues*

\section{Resumo}

Para muitos, a qualidade do ensino da Educação Física e a democratização da cultura corporal não são objetos de problematização, pois o uso do corpo é algo alheio às preocupações da cultura, compreendida em sentido amplo. No entanto, compreendo que esse é um problema a ser investigado, cujo interesse nasceu de uma reflexão sobre alguns casos vivenciados por mim, como professor de Educação Física, e que serviram de amostra para esta análise. Desse modo, foi possível me defrontar com diversas dificuldades de se pensar a cultura corporal nos espaços destinados a essa disciplina e onde, muitas vezes, se utiliza o corpo para o exercício de práticas autoritárias. Para analisar esse aspecto, serão utilizados conceitos do campo da teoria crítica, partindo da hipótese de que essa matéria encontra-se inviabilizada devido a diversos fatores, dentre os quais podemos destacar a falta de associação entre a teoria e a prática. Grande parte das chamadas teorias educativas trabalhadas no curso de formação de professores não os capacita para uma reflexão sobre os determinantes do real, presentes no ato educativo que, no caso específico do ensino da Educação Física, está relacionado às práticas corporais ou à transmissão das técnicas de corpo. O método utilizado para a coleta de dados foi o da pesquisa participativa, oportunizada pelo contato com a escola. Os resultados desta investigação indicam que a qualidade nas aulas de Educação Física e a democratização da cultura, encontram-se diretamente relacionadas à implicação e à responsabilidade dos sujeitos envolvidos em sua realização.

Palavras-chave: Práticas Curriculares. Educação Física Escolar. Educação de Corpo. Técnicas de Corpo.

M inha primeira e efetiva prática de ensino ocorreu na condição de aluno do curso de Educação Física da Universidade Estadual Paulista Júlio de Mesquita Filho (UNESP), do campus de Rio Claro, onde desenvolvi no ano de 1986, durante o estágio supervisionado numa creche, aulas para crianças nas faixas etárias de quatro e cinco anos. Tive, então, minha primeira oportunidade de refletir sobre a prática da Educação Física e, nesse momento, pude constatar o problema da falta de unidade entre a teoria e a prática, ou seja, o plano de aula (teoria) a partir do qual se buscava trabalhar a Educação Física Infantil se apresentava completamente destituído de relação com os determinantes da prática.

No tempo em que eu permanecia na creche, os alunos
* Doutor em Educação pela Unicamp, Docente da Universidade Federal de Itajubá - MG | Agradeço a UNIFEI e a FAPEMIG pelo apoio financeiro na realização desta pesquisa (Edital 13/2012 - Pesquisa em Educação Básica - acordo CAPES-FAPEMIG - PROCESSO No. : CHE - APQ03301-12)

Revista @rquivo Brasileiro de Educação, Belo Horizonte, vol.1, num.2, jul - dez, 2013. 
simplesmente corriam de um lado para o outro. Não conseguia sequer realizar a aula que havia planejado e, principalmente, não compreendia os motivos dessa falta de vínculo entre o "eu" e o "outro", isto é, entre mim e meus alunos.

Compreendi parte das causas desse problema educativo quando, um dia, cheguei mais cedo e pude observar um fato que me causou espanto e certo mal estar. Todos os alunos da turma para a qual eu iria dar aula estavam em uma atitude estranha: de pé, em fila, imóveis e com seus rostos encostados na parede. Eles estavam sendo vigiados pela "tia educadora", cujo tom de voz era semelhante ao de um sargento passando ordens de comando a seus soldados: "agora vocês podem ir para a aula de Educação Física!".

Parti da suposição de que essa modalidade de educação física, aplicada pelas "tias educadoras", se constituía num eficiente mecanismo de controle, que promovia seus efeitos na subjetividade daquelas crianças. Pude, dessa maneira, verificar um tipo de educação corporal que unia a prática e a teoria na constituição de resultados emocionais que se realizava na imposição da imobilidade do corpo daquelas crianças.

Foi possível considerar, também, que impedir a execução de movimento corporal humano seria algo muito eficaz na produção de uma determinada subjetividade que pode ser percebida pela condição daquele que se encontra na posição de subordinado. Assim sendo, a eficácia do castigo corporal estava, justamente, na condição de impor às crianças aquela situação de imobilidade. Elas apresentavam-se como "estacas espetadas no solo" e aquela ordem de comando deveria ser interpretada como: "estão livres para se movimentar".

Naquele momento, eu me perguntava: como elas poderiam aceitar a outro tipo de Educação Física, depois de ficarem por tanto tempo fazendo uma "educação física" que as deixava sem se movimentar conforme o seu próprio desejo?

Desse modo, pude compreender, em parte, a reação dos alunos àquele comando, ou seja, aquelas palavras produziam uma ação comparada a um ato de resistência e de repulsa a qualquer educação do corpo que os sequestrasse e produzisse algo alheio aos seus desejos.

A partir dessa reflexão, minha interpretação inicial foi a de que

Revista @rquivo Brasileiro de Educação, Belo Horizonte, vol.1, num.2, jul - dez, 2013. 
tanto a fuga das atividades como a impossibilidade de realizar o meu "plano de aula" seria uma forma inusitada de resistência do corpo, sendo esse compreendido pelas crianças como lugar de exercício do suplício e em que o castigo corporal faz parte de uma "rede institucional de sequestro". (FOUCAULT, 1996, p. 115).

As diversas redes institucionais de sequestro têm como papel principal o controle de toda dimensão temporal de vida dos indivíduos e dos corpos dos sujeitos (FOUCAULT, 1996). Assim sendo, aquela ação inesperada em que todas as crianças fugiam do "tio da Educação Física", isto é, do professor, passa a ser compreendida como uma ruptura com a imposição da disciplina de Educação Física e como uma resistência espontânea das crianças em participarem dessa aula, mas tendo como base o "princípio de realidade", ou seja, optando em levar os seus corpos para algum lugar em que ninguém pudesse encontrá-los e submetê-los a algo alheio ao seu próprio desejo.

Interessa perceber que, nessa situação, uma mensagem ficava estabelecida entre as "tias educadoras" e o "tio educador físico", ou seja: elas sabiam como controlar as crianças. Já o "tio educador físico", aparentemente, era aquele que não tinha nenhuma habilidade para o "controle da turma". Nesse caso, as crianças passavam também a ser objetos de disputa, sendo utilizadas para indicar uma condição do poder da "tia educadora" na expressão de potência, isto é: eu consigo controlar e dominar o outro, e você, que se apresenta como educador físico, não domina esse saber prático.

Em relação ao controle disciplinar, ouvi uma descrição a respeito das táticas utilizadas por uma professora do ensino fundamental com essa finalidade. Ao expor sua metodologia educacional, ela deu o seguinte depoimento:

[...] eu, nos primeiros dias de aula, não dou nenhum sorriso para a turma e entro com a cara brava para que eles tenham medo. Você tem que se impor, caso contrário, eles vão querer dominar, e aí você perde todo o controle da turma. Depois, com o passar do tempo é que você vai se soltando um pouco mais com eles. (RODRIGUES, 2008, p. 32).

Essa fala conecta-se diretamente à fantasia de potência de

Revista @rquivo Brasileiro de Educação, Belo Horizonte, vol.1, num.2, jul - dez, 2013. 
diversos educadores que se encontram na condição única do exercício do poder e do controle sobre o outro. Essa forma de atuação do educador está presente também em diversos pais e professores. Nesse sentido, a condição de educar está diretamente relacionada à possibilidade de fazer do outro um reflexo de quem o domina. Para tanto, o outro tem que assumir uma condição de objeto que adquire certa plasticidade e que vai se moldando, conforme as forças que se impõem sobre seu corpo. A todo o momento, projetamos no outro os nossos desejos, principalmente quando se trata de algo como o nascimento de uma criança educada por meio de uma concepção autoritária.

\begin{abstract}
O nascimento de uma criança é um acontecimento que parece completamente trivial e despojado de qualquer mistério: algo habitual que se submete, sem qualquer dificuldade, à lógica daquilo que é normal, daquilo que pode ser previsto e antecipado. A extrema vulnerabilidade do recém-nascido torna absoluto o nosso saber, que nele não encontra nenhum obstáculo. Podemos, sem nenhuma resistência, projetar nele nossos desejos, nossos projetos, nossas expectativas, nossas dúvidas e nossos fantasmas. Inclusive, sua fragilidade e suas necessidades abrem-se com absoluta transparência àquilo que nós podemos the oferecer, à medida de nossa generosidade. [...] Dir-se-ia que o recém-nascido não é outra coisa senão aquilo que nós colocamos nele. (LARROSA, 2004, p. 186-187).
\end{abstract}

A condição de permanência dos sujeitos dominadores nesse tipo de atuação encontra-se no modo como se orgulham de poder fazer do outro um objeto sem vontade própria, que faz apenas aquilo que lhe é exigido. Nesse caso, é importante destacar que o ensino da Educação Física poderia surgir como um mecanismo de resistência à atuação do sujeito autoritário, sendo que, para tanto, é preciso compreender o conjunto das práticas corporais. O exercício do autoritarismo pode se apresentar espontaneamente em diversas atuações dos sujeitos como se pode ilustrar com o que ocorreu em uma aula prática, do meu curso de formação de educador físico, em que havia um professor que propunha certa "brincadeira": "quem não conseguir fazer o exercício corporal solicitado, vai ter que pagar com dez apoios de solo".

O referido professor mudou de postura no dia em que nós, na condição de alunos do curso, perguntamos: "como podemos ensinar a Educação Física se você considera o exercício corporal uma espécie de

Revista @rquivo Brasileiro de Educação, Belo Horizonte, vol.1, num.2, jul - dez, 2013. 
castigo?". Ele tentou se justificar dizendo que se tratava de uma forma de motivação para a turma.

São diversos os tipos de explicações e de ações que, tidas como "brincadeiras", reforçam o autoritarismo em diversos modos de manifestações e, no caso dos castigos corporais, tem sua hegemonia no social. Podemos encontrar no corpo um lugar passível de aplicação de forças coercitivas e isso é aceito de maneira consensual, simplesmente pelo fato de que esse se apresenta como um território livre para ser explorado e pouco demarcado pela criticidade em seu uso técnico.

Na questão do uso técnico do corpo, faz-se necessário romper, de modo geral, com os palpites e opiniões, sendo preciso que o intelectual da Educação Física se constitua como aquele que faça crítica às modalidades de práticas corporais e que conheça suas raízes e concepções de mundo. Um praticante de Kendo, por exemplo, deve saber que faz algo relacionado à prática samurai de luta com espadas e que, ao entrar numa área de luta, está ingressando numa estrutura que o submete ao mundo do Japão feudal. Nesse lugar, os treinamentos corporais são os exercícios em que o corpo é submetido a um controle ostensivo, para que venha a alcançar a superação da dor e do cansaço. Fazer Kendo sem compreender seu significado seria uma apropriação superficial da técnica corporal.

Voltando à análise das dificuldades enfrentadas na creche o problema ressurge, pois como seria possível ensinar Educação Física se a "tia educadora" fazia uso do corpo daqueles alunos de forma autoritária? Nesse caso, apresenta-se a outra parte da minha compreensão sobre os motivos de eu não conseguir realizar as aulas forma prática. Percebi que não foi produzido por mim, naquele momento, um tipo de reação que pudesse se consolidar também como uma modalidade de resistência e ruptura com as práticas institucionais de sequestro.

Além de constatar a dificuldade na realização da unidade entre teoria e prática, tive como primeiro ensinamento que, sem um "projeto pedagógico", torna-se inviável qualquer prática de ensino. O modo como as crianças se recusavam a fazer a minha aula na creche poderia ter sido interpretado como: "faça algo melhor do que esse ato que castiga os nossos corpos e mentes".

Encontrar o ponto de fuga que viabilize uma ruptura e promova o

Revista @rquivo Brasileiro de Ẽducação, Bèlo Ḧorizonte, vol.1, ñum.2, jul - đ̄éż, 2013. 
exercício da Educação Física escolar democrática e emancipatória é algo que necessita ser identificado, pois se trata de uma reflexão a partir do real, que se apresenta como "síntese de múltiplas determinações" (MARX, 1983, p. 218). A interpretação do real poderia possibilitar o surgimento da esperança de se compreender os limites e as possibilidades da realização da Educação Física escolar, principalmente por ela ser delimitada pela formação do profissional e pelo mercado de trabalho.

\section{A qualidade na educação: alguns apontamentos sobre a Educação Física escolar}

A falta de associação entre a teoria e a prática, que se apresenta nas teorias educativas trabalhadas no curso de formação dos professores, constitui uma restrição para que seja feita uma reflexão sobre o real educativo, principalmente quando as chamadas teorias educativas são pronunciadas como dogmas passíveis de apreender o real. Isso favorece o surgimento de práticas de autoritarismo, pois o sujeito educador acaba por se impor na condição de impedir qualquer tipo de atitude que se oponha ao seu pensamento ou modo de agir.

Uma reação a essa ampliação do autoritarismo no campo educacional, deveria estar no centro dos debates por aqueles que irão exercer a prática educativa e que, portanto, deveriam ficar atentos aos diversos elementos difusos produzidos no ambiente escolar. Para tanto, os educadores poderiam apresentar em seus conteúdos algo que levasse o sujeito a assumir uma postura crítica que o direcionasse para a elaboração de uma verdade provisória sobre o fazer educativo tendo como base a liberdade e o respeito em relação ao outro. No meu entendimento, são esses os elementos básicos que definem a qualidade na educação e a transmissão da cultura corporal com liberdade de pensamento.

Temos como consequência desse fenômeno educacional algo que denominamos de construção da educação emancipatória. Portanto, adotamos como pressuposto que a Educação Física escolar se produz nas relações inéditas construídas entre os sujeitos, mais propriamente na maneira como o sujeito, no âmbito de sua formação profissional, incorpora 
esse objeto do saber e o acolhe no sentido de poder se sentir realizado no campo do trabalho. No caso específico dessa disciplina, ocorre um tipo de "saber fazer" que se produz e que qualifica o profissional para a construção dessa unidade entre teoria e prática, portanto:

A educação é o modo como as pessoas, as instituições e as sociedades respondem à chegada daqueles que nascem. A educação é a forma com que o mundo recebe os que nascem. Responder é abrir-se à interpelação de uma chamada e aceitar uma responsabilidade. Receber é criar um lugar: abrir um espaço em que aquele que vem possa habitar; pôr-se à disposição daquele que vem, sem pretender reduzi-lo à lógica que impera em nossa casa. (LARROSA, 2004, p. 188).

Nesse caso, a prática educativa se apresenta como um detalhe que, possivelmente, poderá potencializar ou inviabilizar esse "saber fazer" que produz o inédito na educação. No entanto, a formação profissional pode qualificar o professor para atuar na produção desse saber, pois permitirá a ele ampliar seus modos de agir de elaborar metodologias de ensino.

\section{A teoria educacional e as possibilidades de ruptura com o senso comum}

Ao abordar o ensino da Educação Física é preciso focar no ponto central, ou seja, o quanto a prática dessa disciplina é mal compreendida pelos gestores escolares e demais professores da unidade de ensino. Desse modo, ao chegar aos quase 30 anos de docência, considero oportuno fazer uma avaliação de como essas decorrências afetam a democratização da cultura corporal na sociedade brasileira.

É comum, no dia-a-dia, ouvirmos a seguinte afirmação: "É fácil falar, mas o difícil é fazer". Essa frase do senso comum percorre todas as esferas sociais chegando também à unidade escolar com a seguinte variação, para aqueles que se encontram na atividade prática em sala de aula: "Os teóricos da educação somente sabem falar como educar, mas o difícil é o saber como colocar esse princípio em prática".

Revista @rquivo Brasileiro de Educação, Belo Horizonte, vol.1, num.2, jul - dez, 2013. 
O que esse paradigma do senso comum estabelece é que o mundo das práticas educativas encontra-se dissociado do mundo das teorias. Nessa separação, o polo da prática prevalece como verdade sobre o "saber fazer" e as suas determinações se encontram limitadas pelos princípios do fazer. Já o polo da teoria encontra-se na verdade reflexiva e pode apresentar uma precariedade, pois o fazer é também um saber no campo da teoria que pode estar destituído da verdade do saber fazer prático.

Tive a oportunidade de vivenciar, nos anos em que trabalhei na educação básica, como professor de Educação Física, uma forma radical de separação entre a teoria precária e a prática verdadeira. Atuando em diversas unidades escolares, foi possível perceber que a concepção de prática encontrava-se destituída de valor cultural e, portanto, sua presença na escola era algo alheio às dimensões da formação cultural dos sujeitos.

O ensino dessa disciplina era caracterizado como uma prática educativa desprovida de sentido, cabendo ao professor assumir tarefas espontâneas, na relação de ensino com os alunos, que se restringiam ao "jogar bola". O problema não estava nessa atividade, e sim no momento em que o professor não atribuía um significado à prática realizada, caracterizando-a como uma ação espontânea e sem significado cultural, ou seja, o exercício da prática pela prática.

Não posso deixar de lembrar que, como aluno de Educação Física, nos dias em que tinha aula, o professor nos mandava correr sem explicar o motivo daquilo. Devíamos apenas obedecer a esse fazer prático para atender a uma demanda sem qualquer significado. Práticas de corridas e outras formas de treinamento só passaram a fazer sentido em minha existência quando foram associadas ao desejo de aprimorar determinadas técnicas corporais (MAUSS, 1974). Surgem, então, as seguintes questões: por quais motivos as práticas curriculares presentes no ensino da Educação Física não fazem dessa disciplina uma oportunidade para que os alunos compreendam criticamente o uso do corpo na sociedade moderna? Não seria esse o papel primordial do aparelho escolar no ensino crítico da educação corporal?

O que se pode observar, ainda nos dias de hoje, é que, enquanto as outras disciplinas da unidade escolar são tidas como práticas educativas

Revista @rquivo Brasileiro de Educação, Belo Horizonte, vol.1, num.2, jul - dez, 2013. 
de conteúdos teóricos, o ensino da Educação Física é considerado uma prática corporal sem sentido algum, pois os alunos pedem e, principalmente, imploram ao professor para "jogar a bolinha".

Essa tendência, observada em diversas aulas de Educação Física espalhadas por todos os lados, de focar somente no "jogar a bolinha", fez com que toda a falta de compreensão sobre a natureza do ato educativo fosse direcionada para o ensino dessa disciplina. Ainda hoje, é comum se repetir, como um verdadeiro mantra, que o ensino dessa matéria se encontra destituído de valor cultural.

Bourdieu (1990) indica o campo das práticas corporais como pouco explorado, a ponto de compará-lo a um gueto, em que os intelectuais não entram e os esportistas que estão incluídos não saem. A formação desse gueto é consequência daqueles que se recusam a pesquisar as práticas corporais ou daqueles que as pesquisam, mas recusam que outros referenciais teóricos possam analisá-las (BOURDIEU, 1990). Esse nó prevalece nessas atitudes, pois, de um lado, quem atua com a prática da Educação Física não pensa a teoria, e do outro, quem trabalha com a teoria não participa das atividades práticas.

Esse isolamento que a prática dessa disciplina encontra na unidade escolar acabou produzindo os seguintes discursos, que são proferidos diversas vezes: "Nossa, que vontade de ser professor de Educação Física, pois não precisa corrigir prova!"; "Nesse calor deve ser bom ficar no pátio!"; "Deve ser divertido dar aula de Educação Física, porque não é preciso preparar aula". Enfim, é um conjunto de frases que caracterizam uma falta de compreensão sobre o papel primordial da unidade escolar em transmitir cultura e, nesse caso específico, a cultura corporal.

O que mais impressionava nessas diversas falas era a afirmação de que os estudantes não aprendiam por falta de interesse e por serem preguiçosos. Paradoxalmente, os alunos que se encontravam nas aulas eram ativos e curiosos. Isso era explicado também pelos de educadores que apresentavam outras atitudes preconceituosas e sentimentos de revolta em relação à Educação Física, no sentido de desqualificá-la como teoria e prática educativa, caracterizando-a como apenas jogos e brincadeiras sem significado, colocando-a em oposição aos conteúdos teóricos da sala de aula.

Para esses educadores, a escolha daquilo que poderia ser ou não

Revista @rquivo Brasileiro de Educação, Belo Horizonte, vol.1, num.2, jul - dez, 2013. 
conteúdo escolar estava relacionado ao grau de dificuldade em aprender e a seriedade na relação educativa. Em oposição a esse argumento, defendiam que a Educação Física é fácil de aprender e, principalmente, divertida, portanto não seria conteúdo escolar. O discurso sobre a não importância dessa disciplina chegou ao extremo, pois ela poderia até deixar de existir na unidade de ensino. Por meio de uma determinação legal, ficou estabelecido, no artigo 26, parágrafo $3^{\circ}$, da nova Lei de Diretrizes e Bases da Educação Nacional (LDB), que a Educação Física deverá integrar à proposta pedagógica da escola como componente curricular da educação básica e facultativa nos cursos noturnos (BRASIL, 1996).

Por qual motivo o estudante do curso noturno não faria Educação Física? Seria pelo fato de ser um aluno trabalhador, já estar exausto e, portanto, pouco disposto a realizar uma atividade com o seu corpo? As justificativas são diversas. Ora possuem base argumentativa de caráter biológico, ora possuem a concepção de que o uso técnico do corpo é resultado da cultura. Independentemente dos motivos, diríamos de um modo direto que assistimos à desobrigação do Estado em oferecer aulas de Educação Física de qualidade para os alunos, principalmente nos cursos noturnos.

O resultado dessa flexibilização da lei educacional acaba por materializar-se no ensino espontâneo de práticas corporais, o que podemos constatar, nos tempos atuais, na consolidação da Educação Física escolar bifurcada na ambivalência de um duplo significado, ou seja, sendo desvalorizada como uma "pedagogização da educação do corpo" e hipervalorizada como "esportivação da educação do corpo".

A partir desse duplo sentido, essa prática se constitui como espelho distorcido do fenômeno esportivo, mais propriamente como uma pseudoesportivização do uso técnico do corpo nessas aulas. Entretanto, resta sabermos os motivos de a Educação Física escolar tentar encontrar no esporte-espetáculo um suporte e uma valorização de sua prática educativa. Aqueles que trabalham nessa área expandem os sintomas narcísicos em relação aos cuidados com o corpo, sendo que, na sociedade de massa, o esporte passa a constituir-se como uma imagem/ objeto que possibilita o processo identificatório. (LACAN, 1998).

O esporte não movimenta somente as mercadorias numa 
sociedade de massa, movimenta também o fascínio e atração pelo consumo de um determinado tipo de corpo e, consequentemente, de um "bem estar". No caso da escola, esse fenômeno é traduzido pelo vislumbre da monocultura esportiva do futebol, ou seja, o conteúdo escolar efetivo realizado nas aulas de Educação Física. De um modo geral, sobressai a prática do "jogo de bola com os pés", denominada no "campo esportivo" como "futsal" e cuja ênfase é dada somente no resultado ou no desempenho do "aluno/jogador". Essas aulas acabam se transformando em torneios e campeonatos, ou seja, uma miniatura do fenômeno esportivo amplamente divulgado na "sociedade de massa" ${ }^{1 "}$.

Nessa prática corporal espontânea, tanto os alunos quanto os professores não se apropriam da totalidade do trabalho com o esporte, sendo que, a qualquer momento, o aluno poderá perguntar: "professor, você vai 'dar' bola hoje?", e como uma plena associação, o professor dirá: "vamos bater uma bolinha?". Nesse aspecto, o ensino da Educação Física acaba se estabelecendo nos estereótipos esportivos, prevalecendo o senso comum no uso das habilidades motoras. Desse modo, as qualidades físicas são pouco trabalhadas. O mesmo ocorre com a formação cultural, com certo grau de crítica no uso técnico do corpo.

O objetivo de fazer da educação física algo comprometido com a transmissão da cultura é uma decorrência do trabalho qualificado e de uma prática educativa pautada na responsabilidade e na autoridade em transmitir o saber.

No processo de transmissão do saber, a unidade escolar deveria se pautar no pressuposto de que o grau de seriedade está diretamente relacionado ao modo como se compreende a ciência e, principalmente, suas possibilidades de repassar informações.

A ideia das aulas de Educação Física como sendo "jogos" e "brincadeiras" é difundida como verdadeira, o que a torna uma prática educativa das mais interessantes. As explicações que recebi sobre essa discordância entre a teoria e a prática foram as de que essas aulas são consideradas divertidas e que os alunos gostam de "brincar de jogar". No entanto, não seria esse justamente o ponto problemático do ensino, ou seja, uma educação que não diverte e na qual o aluno não brinca em oposição a um modelo que, além de brincadeiras e diversões, também transmita os conteúdos escolares? Será que todos os conteúdos escolares
$1 \mathrm{O}$ fortalecimento do conteúdo da Educação Física como sendo a prática do esporte, mais propriamente a prática do futebol, chega a determinar a arquitetura das escolas nas construções das "quadras poliesportivas".

Revista @rquivo Brasileiro de Educação, Belo Horizonte, vol.1, num.2, jul - dez, 2013. 
não deveriam se tornar atraentes para os alunos?

Para tanto, tais conteúdos deveriam também ser atraente para educador, pois como pode desejar que o aluno aprenda se ele próprio não almeja o saber? É comum encontrarmos nas unidades escolares professores cansados de assumir o papel de transmissores de conteúdos. A natureza dessa profissão requer um tipo de personalidade envolvida plenamente com a erudição para que o momento da aula seja transformado em algo significativo para a sua vida e não em algo alheio à sua construção como sujeito.

Uma atitude muito comum entre os professores é estabelecer certa hierarquia no campo do saber, sendo que alguns deles possuem uma concepção do bom ensino como tudo aquilo que é difícil de aprender e, portanto, de maior valor acadêmico. A falência da educação é um discurso hegemônico no qual é possível encontrar diversas afirmações em que:

Não faltam explicações "pedagógicas" para compreender o "aluno anormal", mais propriamente o "fracasso escolar", as quais centram-se na tese de uma falta de adequação, ou relação natural, entre a intervenção do adulto e o estado psicomaturacional das crianças e dos jovens. Assim, oscila-se entre afirmações do tipo 'ainda não está maduro para uma tal atividade' e o 'método utilizado revelou ser pouco eficaz'. (LAJONQUIÈRE, 1999, p. 28).

Independentemente de onde venha a explicação sobre o fracasso escolar, o que temos são elementos presentes na unidade de ensino que se apresentam como impeditivos para a formação intelectual, pois para o ingresso do aluno na sociedade do mercado prevalece o padrão de qualidade, isto é, o ensino institucionalizado.

No entanto, a compreensão do fracasso escolar envolve outros fatores em que elementos como motivação e preguiça apresentam-se como resultado, ou, mais propriamente, como a ponta de um iceberg em que a teoria crítica, no campo educacional, pode colaborar para evidenciar os diversos determinantes que se apresentam como integrantes na composição da falência do ensino.

Em parte, devemos assumir que temos um conjunto de formulações teóricas sem fundamento lógico e científico. O problema é que esse tipo de reflexão assume o contexto de elementos práticos, sendo necessário, portanto, fazermos um esforço para inverter essa lógica com o objetivo

Revista @rquivo Brasileiro de Educação, Belo Horizonte, vol.1, num.2, jul - dez, 2013. 
de pensar filosoficamente os motivos do fracasso escolar.

O campo educacional é um lugar em que todo tipo de reflexão apresenta-se como argumento válido para se estabelecer uma modalidade de ensino, que possa transformar a escola em um local apropriado para o aprendizado. Sendo assim, é preciso que nos dediquemos a essa análise para que se possamos compreender essa esfera da transmissão do saber e para que possamos nos responsabilizar, pelo menos em parte, pelos resultados desses discursos nas práticas educativas do cotidiano.

Podemos observar que esse campo é atravessado por "achismos", em que alguns assumem a tarefa de responder à questão do problema educacional como se fosse a verdade maior em termos de teoria e prática. Nesse caso, é comum os professores de sala de aula se posicionarem como aqueles que possuem um saber prático específico, criando certa aversão aos teóricos da educação, considerando-os como aqueles que não sabem dar aula e, portanto, que ficam "falando sobre coisas que não se aplicam na prática".

Consideramos que essa dicotomia entre a teoria e a prática é o ponto crucial que desqualifica, em parte, o campo educacional, pois identificamos essa oposição como o elemento primordial a ser abordado na construção de práticas educativas efetivamente emancipatórias que possibilitem a democratização da cultura.

\section{A democratização da cultura corporal e o impossível do ensino da Educação Física escolar}

Compreender a unidade escolar como um território em que se disputa a produção de subjetividades é algo que se apresenta como um verdadeiro problema filosófico, ou seja, "[...] Como evitar que as crianças se prendam às semióticas dominantes ao ponto de perder muito cedo toda e qualquer verdadeira liberdade de expressão?". (GUATTARI, 1981, p. 51). Como fazer com que os alunos, nos cursos de formação de professores, possam se capacitar a ponto de poder identificar em sua prática educativa o conjunto de contradições que impedem a constituição 
da crítica do sujeito em relação às coisas da vida?

Compreendo que a luta política é extensa, para começar, alerto muitas vezes aos meus alunos do curso de graduação que o valor pago pela hora aula pode ser de um real, mas a hora aula não vale o referido um real. Portanto, esse valor monetário defasado é, ao longo do tempo, objeto de luta no campo da política, em que o Estado, ou o dono de escola, busca submeter o intelectual a uma determinada forma de poder no que se refere à remuneração paga pelos serviços prestados. Partimos do pressuposto de que o valor da aula está diretamente ligado à interface entre a cultura e as práticas realizadas em sala de aula. $\mathrm{O}$ professor se realiza como o intelectual na medida em que é capaz de abandonar o desejo de controle do sujeito aprendiz e trabalha no sentido de direcioná-lo para a apropriação de elementos culturais e, em se tratando da Educação Física escolar, para constituição daquilo que se pode denominar cultura corporal.

Essa cultura fará parte dessas aulas no momento em que os professores da referida área assumirem a condição de sujeitos responsáveis pela concretização da união entre teoria e prática e pela utilização do corpo para a realização do movimento corporal que possibilite ao sujeito conhecer a si mesmo, ou seja, para o completo abandono de formas educativas espontâneas e desprovidas de crítica, como aquelas citadas como práticas regularmente exercidas nas aulas de Educação Física. O espontâneo torna-se necessário quando aliado a uma cultura que possa permitir ao sujeito elaborar sua condição de existência e, principalmente, a condição de intervir no real.

Para os alunos que perguntam aos seus professores de Educação Física se "vai ter bolinha hoje?", deve-se encontrar a possibilidade de fazer da "bolinha" um objeto de estudo ampliado e com outras possibilidades de utilização do corpo humano. Isto é, como uma possibilidade de se conjugar a prática e a teoria, já que o corpo pode ser utilizado tecnicamente de diversas formas no social, inclusive como uma modalidade de resistência ao modelo de produção capitalista. Issojá seria, em parte, uma condição para se encontrar o sentido na formação escolar e, portanto, na produção de intelectuais que possam pensar a si mesmos e a seus corpos de modo mais completo, no sentido de se buscar uma Educação Física escolar e uma formação profissional comprometida com a humanidade do sujeito, permitindo, também, sua inserção no mercado

Revista @rquivo Brasileiro de Educação, Belo Horizonte, vol.1, num.2, jul - dez, 2013. 
de trabalho. Para finalizar, merece destaque uma inquietação sobre a formação do sujeito educador pelas nossas instituições de ensino: "O leitor do qual espero alguma coisa deve ter três qualidades. Deve se calmo e ler sem pressa. Não deve intrometer-se, nem trazer para a leitura a sua "formação". Por fim, não pode esperar na conclusão, como um tipo de resultado, novos tabelamentos". (NIETZSCHE, 2000, p. 33).

Nessa linha argumentativa, apresento minha esperança na mudança no processo de formação do educador e o meu visível desconforto de, já naquela época, "não saber" atuar como professor daquelas crianças da creche. Hoje, tenho a convicção de que essa situação foi o que motivou minha vontade de me aliar às práticas de resistência a uma Educação Física que oprime os corpos e as mentes dos alunos.

\section{A unidade entre a teoria e a prática: o ensino da Educação Física no campo da teoria crítica}

Seria possível uma concepção de ensino que trabalhasse com a união entre teoria e prática? Em outras palavras, seria possível pensar em práticas educativas que estabelecessem essa junção e promovessem uma modalidade de ensino que fosse atraente para os alunos?

Nesse aspecto, o ensino da Educação Física, e de outras disciplinas, poderia levar à realização de experiências pedagógicas voltadas para o exercício de união entre teoria e prática, pois suas metodologias se revelariam no saber fazer e, consequentemente, produziriam conhecimentos.

As disciplinas teóricas, na unidade escolar, já se encontram em um longo processo de abstração e, em grande parte, já perderam a filiação às práticas sociais, portanto, requerem um longo exercício no campo da filosofia e da ciência para encontrar as motivações práticas que as fizeram se constituir no campo do pensamento.

Desse modo, a teoria crítica seria uma alavanca a ser utilizada para permitir esse alcance na consolidação da união entre a teoria e a prática. Esse exercício intelectual pode ser encontrado no livro Educação Física Progressista, publicado em 1988, que, pautado na teoria crítica dos conteúdos, buscava realizar essa unidade no fazer educativo.

Compreendo que o maior impedimento na construção de uma metodologia de ensino, no campo da teoria crítica, é a recusa em se pensar a necessidade dessa aliança. Buscava-se, nas aulas de Educação

Revista @rquivo Brasileiro de Educação, Belo Horizonte, vol.1, num.2, jul - dez, 2013. 
Física, justamente aquilo que todos os professores já tinham como (pré) conceito, ou seja, uma prática destituída de sentido e transformada em "jogos e brincadeiras" que se apresentavam como parte de um processo alienante, que já estava instaurado no interior do aparelho escolar.

No entanto, com o passar dos anos, foi possível encontrar um sentido para aquilo que, aparentemente, estava dissociado no campo das práticas corporais. As aulas de Educação Física passaram a ser vistas como atividades em que o corpo seria usado e interpretado como um laboratório das relações humanas, em que se encontram presentes os diversos investimentos no campo das pulsões. Portanto, isso poderia configurar outra possibilidade dos sujeitos se representarem e, principalmente, lidarem com suas dificuldades acerca de questões referentes ao amor e ao ódio, em suas relações com o outro. Nesse aspecto, o conteúdo escolar seria apenas um elemento secundário, pois o foco estaria na formação do sujeito no campo da cultura. Diríamos que é preciso circunscrever essa discussão com base na premissa de que:

\begin{abstract}
Nas culturas ocidentais, o corpo humano está fundado num fechamento da carne sobre ela mesma e sobre a humanidade intrínseca e única dessa matéria que traça para o homem seu rosto e sua forma. A separação que distingue o indivíduo de um outro é rigorosa; o corpo de um homem não poderia se misturar estruturalmente ao de um outro. $O$ corpo é o vetor da individualização, ele estabelece a fronteira da identidade pessoal; confundir essa ordem simbólica que fixa a posição precisa de cada indivíduo no tecido social significa apagar os limites identificadores do fora e do dentro, do eu do outro; essa confusão coloca radicalmente em questão a afirmação de si e faz duvidar sobre a natureza do outro. A igualdade do homem consigo mesmo, a identidade de si, implica a igualdade com seu corpo. A condição do homem é corporal. Subtrair-Ihe alguma coisa, ou lhe acrescentar, coloca esse homem em posição ambígua, intermediária. As fronteiras simbólicas são rompidas. (BRETON, 1995, p. 64).
\end{abstract}

Nesse caso, a compreensão não natural do uso técnico do corpo passa a ser um ancoradouro que permite constituir o "território em ser" numa modernidade que não sabemos mais ser "sujeito/corpo", pois tudo se encontra desterritorializado.

Portanto, o reconhecimento do "corpo/território" fica sendo o lugar da realização da "consciência crítica" de um suposto sujeito, mais propriamente um lugar para a "impossível" realização da "educação do corpo" que o permita "conhecer a si mesmo", no descontrole dos

Revista @rquivo Brasileiro de Educação, Belo Horizonte, vol.1, num.2, jul - dez, 2013. 
"destinos das pulsões".

O "sujeito/corpo" apresenta-se como uma fonte de desprazer, pois este se encontra em constante degeneração "condenado à decadência" (FREUD, 1996, p. 85). Assim sendo, compreendemos que a relação que se estabelece entre o "sujeito" e o "corpo" é conflituosa, pois, na medida em que queremos "ser sujeito/corpo/saudável", simultaneamente, buscamos a negação em "ser sujeito/corpo", pois o corpo é a presença da degeneração, mais propriamente, é o indício de que somos passíveis de sentir dor e de sermos vitimados pela morte.

Essa ambivalência entre sentir prazer com o corpo e encontrar nele uma fonte de desprazer, faz com que estabeleçamos com ele uma relação distorcida que oscila entre aproximação e distanciamento. Essa relação pode ser descrita como um sintoma de sua reificação. Assim, passamos a considerá-lo como algo belo e saudável que, por esse motivo, deve ser consumido. Esse ponto de conflito no uso do corpo se apresenta, não por acaso, nas diversas solicitações dos alunos em querer "jogar bolinha", pois, em última instância, o que está em causa é uma necessidade eminente de alienar-se de si mesmo.

O ponto crucial encontra-se nos mecanismos estabelecidos em uma relação momentânea com o uso técnico do corpo, mesmo em práticas alienantes como "jogar a bolinha". O salto qualitativo seria a possibilidade de despertar e de reconhecer essa necessidade de alienação como um ponto de fuga de si mesmo e, principalmente, compreender os motivos que a provocam.

O reconhecimento desses mecanismos de alienação seria compreendido como a possibilidade de evitarmos o exercício pleno de ações autoritárias no ensino do uso técnico do corpo, pois, de algum modo, temos aqueles que se aproveitam desses mecanismos psíquicos da modernidade e ampliam suas forças ao promulgar o saber "ser sujeito/ corpo", ao ditar os modos estreitos da realização da Educação Física.

Temos conhecimento dos resultados dessas ações pedagógicas e da finalidade de tais práticas educativas que desembocam em sociedades autoritárias. Diria que, de certo modo, os resultados de tais práticas educativas são elementos para um estudo posterior, sendo necessário, contudo, indicarmos uma análise preliminar sobre esses resultados apresentando a tese de que aquele que "é severo consigo mesmo adquire o direito de ser severo também com os outros, vingando-se da dor cujas manifestações precisou ocultar e reprimir" (ADORNO, 1995, p. 128). Em 
parte, isso já responde os motivos de nossa preocupação em se pensar em metodologias para a realização de uma Educação Física que indiquem uma educação de corpo, que seja democrática e libertadora, e, mais precisamente, uma prática que elimine seus "fundamentos educacionais" baseados na dor e na humilhação como pressupostos pedagógicos da aprendizagem motora. Portanto, desde já, estabelecemos o quanto é importante, para a construção de uma sociedade democrática, que se estabeleça uma política do corpo que permita a realização de uma Educação Física que tenha em seus princípios as condições efetivas para o exercício do pensamento crítico, ou seja, que sua prática educativa seja "em si" um exercício corporal crítico que uma teoria e prática.

\section{Abstract}

For many people, the quality of Physical Education (PE) teaching and the democratization of the body culture are not objects of questioning, since the use of the body is something extraneous to culture matters understood in a broad sense. However, I believe that it is a subject to be investigated. My interests on it were born from the reflection on some cases experienced by me as a PE teacher, which served as examples for this analysis. This way, I was able to face several difficulties when thinking the body culture in the spaces intended for that discipline, where the body is often used for the exercise of authoritarian practices. Concepts from the critical theory field are used here to analyze this aspect, on the assumption that this discipline is currently not feasible due to several factors, amongst which the lack of association between theory and practice. Much of the so-called educational theories studied in the teacher education course do not prepare teachers for a reflection on the determinants of the real, which are present in the educational act - specifically in the case of PE teaching, this is related to body practice or to the transmission of body techniques. The method used for data collection was participatory research, possible through contact with the school. Results of this investigation indicate that quality in PE classes and democratization of culture are directly related to the involvement and responsibility of those involved in their realization.

Keywords: Curricular practices. School physical education. Body education. Body techniques.

Revista @rquivo Brasileiro de Educação, Belo Horizonte, vol.1, num.2, jul - dez, 2013. 


\section{Referências}

ADORNO, Theodor W. Educação e emancipação. Tradução de Wolfgang Leo Maar. Rio de Janeiro: Paz e Terra, 1995.

BOURDIEU, Pierre. Programa para uma sociologia do esporte. In: BOURDIEU, Pierre. Coisas ditas. Tradução de Cássia R. da Silveira e Denise Moreno Pegorim. São Paulo: Brasiliense, 1990.

BRASIL, Lei n. 9.394. Estabelece as diretrizes e bases da educação nacional. Diário Oficial da União. Brasília, 23 dez. 1996.

BRETON, David Le. A síndrome de Frankenstein. In: SANT' ANNA, Denise Bernuzzi de (Org.). Política do corpo: elementos para uma história das práticas corporais. Tradução de Mariluce Moura. São Paulo: Estação Liberdade, 1995. p. 59-71

FOUCAULT, Michel. A verdade e as formas jurídicas. Tradução Roberto Cabral de Melo Machado e Eduardo Jardim Morais. Rio de Janeiro: Nau, 1996.

FREUD, Sigmund. Lo siniestro. In: FREUD, Sigmund. Obras completas Sigmund Freud. Tradução Luis López-Ballesteros y de Torres. Madrid: Biblioteca Nueva, 1996. p. 82-93. v.3.

FREUD, Sigmund. O mal-estar na civilização. In: FREUD, Sigmund. Obras completas. Tradução de Jayme Salomão. Rio de Janeiro: Imago, 1990. p. 156-196. v. 21.

GHIRALDELLI JÚNIOR, Paulo. Educação física progressista: a pedagogia crítico-social dos conteúdos e a Educação Física brasileira. São Paulo: Loyola, 1991.

GUATTARI, Félix Pierce. As creches e a iniciação. In: GUATTARI, Félix Pierce. Revolução molecular: pulsações políticas do desejo. Tradução de Suely Belinha Rolnik. São Paulo: Brasiliense, 1981. p. 50-55.

LACAN, Jacques. O estádio do espelho como formador da função do eu tal como nos é revelada na experiência psicanalítica. In: LACAN, Jacques. Escritos. Tradução de Vera Ribeiro. Rio de Janeiro: Zahar, 1998. p. 35-49

LAJONQUIÈRE, Leandro de. Infância e ilusão (psico) pedagógicas: escritos de psicanálise e educação. Petrópolis: Vozes, 1999.

LARROSA, Jorge. Pedagogia profana: danças, piruetas e mascaradas. 
Tradução de Alfredo Veiga-Neto. Belo Horizonte: Autêntica, 2004.

MARX, Karl. Introdução à crítica da economia política. In: MARX, Karl. Contribuições à crítica da economia política. Tradução de Maria Helena Barreiro Alves. 2 ed. São Paulo: Martins Fontes, 1983.

MAUSS, Marcel. As técnicas corporais. In: MAUSS, Marcel. Sociologia e antropologia. Tradução de Mauro W. B. de Almeida. São Paulo: EPU/ EDUSP, 1974. 2 v.

NIETZSCHE, Friedrich. Cinco prefácios para cinco livros não escritos. Tradução de Pedro Süssekind. Rio de Janeiro: 7 Letras, 2000.

RODRIGUES, Rogério. As dinâmicas das práticas educativas e os mitossobre as causas das dificuldades escolares: os problemas de aprendizagem, 2008. Projeto de pesquisa. Itajubá: Unifei. 2008 (mimeo).

SANT' ANNA, Denise Bernuzzi de (Org.). Política do corpo: elementos para uma história das práticas corporais. Tradução Mariluce Moura. São Paulo: Estação Liberdade, 1995. 